\title{
EARLY ORAL FEEDING V/S PARENTERAL NUTRITION IN PATIENTS WITH MILD-TO-MODERATE ACUTE PANCREATITIS - A RANDOMISED CONTROL TRIAL
}

\author{
Dilip Amonkar' ${ }^{1}$ Avinash Pujari², Swapnil Solanki ${ }^{3}$, Aneesh Lawande ${ }^{4}$ \\ 1 Professor and HOD, Department of General Surgery, Goa Medical College. \\ ${ }^{2}$ Senior Resident, Department of Paediatric Surgery, Goa Medical College. \\ 3Undergraduate Student, Goa Medical College. \\ ${ }^{4}$ Senior Resident, Department of Paediatric Surgery, Goa Medical College.
}

\section{ABSTRACT}

\section{BACKGROUND}

In acute pancreatitis, traditional treatment has been initial fasting on purpose to avoid activation of proteolytic enzymes and pancreatic enzyme secretion. In the recent years nasoenteric feeding has increasingly been used in clinical practice in patients with pancreatitis; however, there is not enough documented data with respect to early oral refeeding.

The aim of this study was to explore the feasibility and safety of Early Oral Refeeding (EORF) in patients with mild-to-moderate acute pancreatitis.

\section{MATERIALS AND METHODS}

100 patients were randomised in two treatment groups (50 each), early oral feeding ( $<48$ hours) or Total Parenteral Nutrition (TPN). The inclusion criteria were pancreas amylase $>$ or $=3$ times above normal, onset of abdominal pain within $48 \mathrm{~h}$, acute physiological and chronic health evaluation (APACHE) score < 8. Outcome measures were number of adverse events or complications and Length of Hospital Stay (LOHS)

\section{RESULTS}

The LOHS was significantly shorter in the oral feeding group ( 4 vs. 6 days; $p<0.05$ ). There was no difference in the number of adverse events or complications between the two groups.

\section{CONCLUSION}

EORF could shorten the length of hospitalisation in patients with mild-to-moderate AP. Thus in mild-to-moderate acute pancreatitis, EORF was feasible thus avoiding need for nasoenteral tube insertion (nasoenteric tube feeds) and central lines (as in case of TPN) and hence is safe and may accelerate recovery without adverse gastrointestinal events.

\section{KEYWORDS}

Early Oral Feeding, Acute Pancreatitis.

HOW TO CITE THIS ARTICLE: Amonkar D, Pujari A, Solanki S, et al. Early oral feeding v/s parenteral nutrition in patients with mildto-moderate acute pancreatitis - a randomised control trial. J. Evolution Med. Dent. Sci. 2016;5(101):7422-7424, DOI: $10.14260 /$ jemds/2016/1680

\section{BACKGROUND}

Acute pancreatitis is the most common gastrointestinal disease leading to hospital admission and its incidence continues to rise.[1-2] In all $80 \%$ of the patients admitted to the hospital with acute pancreatitis are classified as mild, which resolves in an average of 5 days. [3] The treatment of mild acute pancreatitis is largely supportive including effective pain control, fluid therapy and discontinuation of oral intake until there is near complete resolution of abdominal pain and tenderness. Early Enteral Nutrition (EN) is vital to maintain the mucosal integrity of the Gastrointestinal (GI) tract and helps prevent bacterial translocation and the infection of sterile pancreatic necrosis.[4-5] A recent meta-analysis compared the efficacy of total EN and Total Parenteral

Financial or Other, Competing Interest: None.

Submission 12-11-2016, Peer Review 06-12-2016,

Acceptance 12-12-2016, Published 19-12-2016.

Corresponding Author:

Dr. Avinash Pujari,

Room No. 135,

Gard Hostel, GMC, Bambolim.

E-mail: dr.pujariavinash@gmail.com

DOI: $10.14260 /$ jemds $/ 2016 / 1680$

\section{(c) $(1)$}

Nutrition (TPN), and demonstrated that in patients with predicted severe AP total EN was associated with lower mortality, fewer infectious complications, decreased organ failure and a lesser need for surgical intervention than TPN.[6] However, EN in these studies is usually provided by nasoenteric tube. There has been very few studies done on feasibility and safety of EORF. The practice of discontinuing oral intake until pain is resolved has been based on the fact that premature feeding may cause an exacerbation.

\section{MATERIALS AND METHODS}

This was a single-centre, prospective RCT. The study was carried out at Department of General Surgery, Goa Medical College. The study protocol was approved by the Institutional Review Board (Ethics and Human Research) of our institution.

Consecutive patients with mild acute pancreatitis admitted for reasons of abdominal pain at the Goa Medical College, which is a multispecialty large referral centre, were included in the study based on the following inclusion criteria: (i) Amylase greater than three times the upper limit of normal or greater than two times the upper limit and a computerised tomography scan/USG showing unequivocal acute pancreatitis and peripancreatic inflammation. (ii) Mild acute pancreatitis [absence of pancreatic necrosis, abscess and 
pseudocyst, absence of organ dysfunction, hypotension (Systolic < 90\%)], hypoxaemia (oxygen saturation < 90\%)].[7]

\section{Exclusion Criteria}

(i) Patients with organ dysfunction and neoplasms, postsurgical patients, pregnant women, patients with infections such as TB, HIV/AIDS, severe acute pancreatitis. (ii) Patients with acute pancreatitis who received enteral support via tube feeding or parenteral nutrition and who received parenteral narcotics for abdominal pain on the day of refeeding. (iii) Patients with acute on chronic pancreatitis who were on enzyme supplementation.

Eligible patients were consecutively enrolled and randomised to one of the two groups. Randomisation was based on a computer generated randomisation list. Random allocation sequence, enrolment and assigning participants to the two groups were done by separate individuals. All the patients were kept on initial fasting as per the conventional treatment, prophylactic antibiotics if they were at risk for infection, glucose control (Insulin) if they were at risk for hyperglycaemia, treatment to maintain the homeostasis appropriate fluid resuscitation therapy. Reestablishment of early oral feeding was considered in the first group of patients as soon as abdominal pain, nausea and vomiting had decreased and bowel sounds had returned irrespective of laboratory parameters. While feeding in the other group was started after complete resolution of pain, nausea and vomiting and after stabilisation of the laboratory parameters of the patient. The diet was gradually progressed from clear liquid to a low-fat liquid diet. Hospital discharge was planned on the basis of the resolution of clinical symptoms and the patient's tolerance of a liquid diet for at least 24 hours.

\section{Outcome Measures}

The primary outcome measure was LOHS. The secondary outcome measures were the total duration of fasting (determined from the onset of abdominal pain) and the subjective tolerance to food including the relapse rate and abdominal pain after the first ingestion of orally consumed food and/or the degree of transitional abdominal distension, which were evaluated by an independent assessor who did not know the group assignment. Laboratory findings and complications were also measured.

\section{Statistical Methods}

A sample size of 100 total patients was calculated as required to detect a reduction in the duration of hospital stay of 1 day with $85 \%$ power and a two-sided $P$ value of 0.05 . Continuous variables were expressed as mean \pm SD if they were normally distributed and median and interquartile range if they were non-normally distributed. Categorical variables are expressed as frequency count. We used ' $\mathrm{t}$ ' test or $\chi^{2}$ test in our study. $\mathrm{P}<$ 0.05 was considered statistically significant.

\section{RESULTS}

On the day of oral refeeding, mean serum amylase had not normalised in the EORF group and all biochemical markers except serum triglyceride and cholesterol levels and haematocrit value were significantly higher in the EORF group than in the delayed oral refeeding group (Table No. 1). At the final measurement before discharge, there was no statistically significant difference between the two groups in any major biochemical parameter other than mean blood glucose level, which was higher in the EORF group than in the DORF group (Table No. 2).

\begin{tabular}{|c|c|c|c|}
\hline & $\begin{array}{c}\text { EORF } \\
\text { (n=50) }\end{array}$ & $\begin{array}{c}\text { DORF } \\
\text { (n=50) }\end{array}$ & $\begin{array}{c}\text { P- } \\
\text { value }\end{array}$ \\
\hline $\begin{array}{c}\text { Serum Amylase } \\
\text { (IU/L) }\end{array}$ & $312 \pm 353$ & $104 \pm 100$ & 0.01 \\
\hline WBC Count (×109/L) & $10.2 \pm 2.8$ & $8.1 \pm 5.2$ & 0.01 \\
\hline Haematocrit & $0.36 \pm 0.05$ & $0.37 \pm 0.05$ & 0.24 \\
\hline $\begin{array}{c}\text { Blood Glucose } \\
\text { (mmol/L) }\end{array}$ & $9.3 \pm 3.5$ & $8.1 \pm 3.4$ & 0.04 \\
\hline $\begin{array}{c}\text { Serum Triglyceride } \\
\text { (mmol/L) }\end{array}$ & $2.6 \pm 2.3$ & $3.6 \pm 5.5$ & 0.20 \\
\hline $\begin{array}{c}\text { Serum Cholesterol } \\
\text { (mmol/L) }\end{array}$ & $4.1 \pm 2.0$ & $4.1 \pm 2.5$ & 0.55 \\
\hline
\end{tabular}

Table 1. Laboratory Parameters Before Oral Refeeding

\begin{tabular}{|c|c|c|c|}
\hline & $\begin{array}{c}\text { E0RF } \\
(\mathbf{n = 5 0})\end{array}$ & $\begin{array}{c}\text { DORF } \\
(\mathbf{n = 5 0})\end{array}$ & $\begin{array}{c}\text { P- } \\
\text { value }\end{array}$ \\
\hline $\begin{array}{c}\text { Mean WBC Count } \\
\left(\times 10^{9} / \mathrm{L}\right)\end{array}$ & $8.7 \pm 4.9$ & $6.8 \pm 5.5$ & 0.06 \\
\hline Haematocrit & $0.35 \pm 0.04$ & $\begin{array}{c}0.35 \pm \\
0.05\end{array}$ & 1.00 \\
\hline $\begin{array}{c}\text { Blood glucose } \\
(\mathrm{mmol} / \mathrm{L})\end{array}$ & $7.9 \pm 3.2$ & $6.4 \pm 2.1$ & 0.01 \\
\hline $\begin{array}{c}\text { Serum triglyceride } \\
(\mathrm{mmol} / \mathrm{L})\end{array}$ & $3.7 \pm 2.3$ & $3.1 \pm 3.4$ & 0.23 \\
\hline $\begin{array}{c}\text { Serum cholesterol } \\
(\mathrm{mmol} / \mathrm{L})\end{array}$ & $44 \pm 3.6$ & $43.7 \pm 1.1$ & 0.56 \\
\hline \multicolumn{2}{|c|}{ Table 2. Laboratory Parameters Before Discharge } \\
\hline
\end{tabular}

There was a significant difference in the post-refeeding LOHS and total LOHS between the two diets (Table 2). The median post-refeeding LOHS was 6 days in DORF and 4 days in EORF (Interquartile range $4-8$ in CLD; 2 - 5 in SD). The corresponding mean post-refeeding $\mathrm{LOH}$ were 6.75 (s.d. 3.37) and 4.18 (s.d. 2.9) days for the EORF and DORF groups respectively. The total LOHS from hospital admission was also significantly different in both groups with EORF group having a shorter total LOHS (DORF: median 8 days, Interquartile Range (IQR) 6 - 9 days, mean 8.71, s.d. 4.995; EORF: median 5 days, Interquartile Range (IQR) 4 - 7 days, mean 5.92, s.d. 2.978; $\mathrm{P}<0.001$.

\begin{tabular}{|c|c|c|c|}
\hline Outcome & $\begin{array}{c}\text { DORF } \\
\text { (n=50) }\end{array}$ & $\begin{array}{c}\text { EORF } \\
\text { (n=50) }\end{array}$ & $\begin{array}{c}\text { P } \\
\text { value }\end{array}$ \\
\hline $\begin{array}{c}\text { Length of } \\
\text { Hospitalisation } \\
\text { Post-Refeeding } \\
{[\text { Median (IQR)] }}\end{array}$ & $6(4-8)$ & $4(2-5)$ & $<0.001$ \\
\hline $\begin{array}{l}\text { Total Length of } \\
\text { Hospitalisation } \\
{[\text { Median (IQR)] }}\end{array}$ & $8(6-9)$ & $5(4-7)$ & $<0.001$ \\
\hline \multicolumn{3}{|c|}{ Table 3 } \\
\hline
\end{tabular}

\begin{tabular}{|c|c|c|c|}
\hline & EORF & DORF & P value \\
\hline Abdominal Pain Relapse & $7(10.5)$ & $10(14.1)$ & 0.51 \\
\hline Abdominal Distention & $8(12.0)$ & $8(11.3)$ & 1.00 \\
\hline \multicolumn{4}{|c|}{ Table 4. Complications } \\
\hline
\end{tabular}




\section{DISCUSSION}

Prolonged parenteral feeding cause adverse-effects such as atrophy and increased permeability of the gut mucosa. Furthermore, due to the lack of peristaltic stimulation there is hypomotility of the gut and the stagnant bowel contents also cause significant changes in the intestinal microflora. Conversely, enteral feeding prevents the atrophic changes as the uptake of nutrients in intestinal epithelial cells comes directly from the intestinal lumen. In addition, enteral feeding facilitates gut motility due to hyperosmolarity of the nutrients. These pathophysiological mechanisms protect against the overgrowth of abnormal intestinal flora and increased gut permeability, hence potentially alleviating subsequent bacterial translocation.

Over the last decade, studies have proven that EN is preferred over PN.[8] However, there is insufficient information on the criteria for initiating oral refeeding in AP patients. Most of the studies advocate early enteral feeds via nasoenteric tubes. The usual criteria for reinitiating oral feeding are the absence of abdominal pain, nausea and vomiting and the restoration of appetite and normalisation of laboratory findings including serum amylase and lipase levels. In the present study, we investigated an alternative approach to reinitiating feeding that was early oral refeeding without the complete remission of abdominal pain or normalisation of pancreatic amylase. Our results demonstrated that EORF based on this approach decreased the duration of both fasting and hospitalisation. These benefits are consistent with the European Society for Clinical Nutrition and Metabolism guidelines which state that "oral food intake should be tried as soon as possible" and Eckerwall et al[9] study which was the first to demonstrate the feasibility of administration of an oral diet an average of $3 \mathrm{~d}$ after hospital admission.[9] No differences were found in amylase values or the systemic inflammatory response between the two groups.

A major concern of EROF in AP is premature oral refeeding with intolerance to the reintroduced diet, which can cause AP relapse and prolonged LOHS. Our study showed that there were no differences between EORF and DORF in terms of abdominal pain relapse, abdominal distension, organ failure and local pancreatic complications suggesting that the EORF is feasible in patients with mild-to-moderate AP.

We have also observed failure to tolerate initial oral feeding, because of pain in $10 \%$ of our study group. But the incidence of failure in both the groups appears the same.
Several Limitations to our Work should be Recognised

1. One of the criteria for starting feeds includes abdominal pain, which is a subjective reference.

2. This study was conducted in a single centre. Although, this centre sees a large volume of patients with AP, caution should be taken when generalising the results of our study.

\section{CONCLUSION}

EORF could shorten the length of hospitalisation in patients with mild-to-moderate AP. Thus in mild-to-moderate acute pancreatitis, EORF was feasible, thus avoiding need for nasoenteral tube insertion (nasoenteric tube feeds) and central lines (as in case of TPN). Hence, it is safe and may accelerate recovery without adverse gastrointestinal events.

\section{REFERENCES}

1. Peery AF, Dellon ES, Lund J, et al. Burden of gastrointestinal disease in the United States: 2012 update. Gastroenterology 2012;143(5):1179-87.

2. Fagenholz PJ, Castillo CF, Harris NS, et al. Increasing United States hospital admissions for acute pancreatitis, 1988-2003. Ann Epidemiol 2007;17(7):491-7.

3. Uomo G. Pancreatic head mass: how can we treat it? acute pancreatitis: conservative treatment. J Pancreas 2000;1(3Suppl):130-7.

4. Meier R, Ockenga J, Pertkiewicz M, et al. ESPEN guidelines on enteral nutrition: pancreas. Clin Nutr 2006;25(2):27584.

5. Qin HL, Su ZD, Hu LG, et al. Effect of early intrajejunal nutrition on pancreatic pathologic features and gut barrier function in dogs with acute pancreatitis. Clin Nutr 2002;21(6):469-73.

6. Yi F, Ge L, Zhao J, et al. Meta-analysis: total parenteral nutrition versus total enteral nutrition in predicted severe acute pancreatitis. Intern Med 2012;51(6):523-30.

7. Mark F, Lawrence FS, Lawrence BJ. Sleisenger and fordtrans gastrointestinal and liver diseases. $8^{\text {th }}$ edn. Philadelphia, PA: WB saunders company 2006:1242-60.

8. Petrov MS, Windsor JA. Nutritional management of acute pancreatitis: the concept of gut rousing. Curr Opin Clin Nutr Metab Care 2013;16(5):557-63.

9. Eckerwall GE, Tingstedt BB, Bergenzaun PE, et al. Immediate oral feeding in patients with mild acute pancreatitis is safe and may accelerate recovery--a randomized clinical study. Clin Nutr 2007;26(6):758-63. 